\title{
Cost-effective Method of Analysis for the Determination of Cadmium, Copper, Nickel and Zinc in Cocoa Beans and Chocolates
}

\author{
Gideon Ramtahal ${ }^{1}$, Ivan Chang Yen ${ }^{1}$, Isaac Bekele ${ }^{2}$, Frances Bekele ${ }^{3}$, Lawrence Wilson ${ }^{2}$, Balmatee Sukha ${ }^{4} \&$ \\ Kamaldeo Maharaj ${ }^{4}$ \\ ${ }^{1}$ Department of Chemistry, The University of the West Indies, St. Augustine Campus, Trinidad \&Tobago \\ ${ }^{2}$ Department of Food Production, The University of the West Indies, St. Augustine Campus, Trinidad \&Tobago \\ ${ }^{3}$ Cocoa Research Centre, The University of the West Indies, St. Augustine Campus, Trinidad \&Tobago \\ ${ }^{4}$ Ministry of Food Production, Land and Marine Affairs, Centeno, Trinidad \&Tobago \\ Correspondence: Gideon Ramtahal, Department of Chemistry, The University of the West Indies, St. Augustine \\ Campus, Trinidad and Tobago. Tel: 1-868-795-0997. E-mail: gideon.ramtahal@sta.uwi.edu
}

Received: May 21, 2014 Accepted: November 10, 2014 Online Published: December 29, 2014

doi:10.5539/jfr.v4n1p193 URL: http://dx.doi.org/10.5539/jfr.v4n1p193

\begin{abstract}
The determination of heavy metals in cocoa beans and chocolates is of great importance, due to increasingly stringent regulations being implemented by international legislative bodies and chocolate manufacturers, to protect the health of their consumers. While various techniques exist for heavy metal analyses in cocoa, this study developed a cost-effective, accurate and precise method capable of processing up to 120 samples per batch for the determination of cadmium, copper, nickel and zinc. For sample extractions, a normal laboratory hot plate and locally fabricated high-capacity digestion blocks were used, instead of dedicated block digestion or microwave digestion systems. In addition, only concentrated nitric acid was used, instead of mixed reagents used in standardized methods, for metal extractions from samples, with a sample: extractant ratio of $0.5 \mathrm{~g}: 10 \mathrm{~mL}$, digestion at $130{ }^{\circ} \mathrm{C}$, followed by filtration and analysis by flame atomic absorption spectrophotometry. The method was validated with Certified Reference Materials, with heavy metal recoveries generally $>95 \%$. Additionally, an in-house quality control sample of ground cocoa nib analyzed together with the Certified Reference Materials was used to monitor the consistency of analyses of heavy metals in cocoa bean samples.
\end{abstract}

Keywords: method, heavy metals, cocoa, chocolate

\section{Introduction}

Food is one of the main sources of heavy metal intake in consumers (Zukowska \& Biziuk, 2008). Some are essential nutrients $(\mathrm{Cu}, \mathrm{Ni}, \mathrm{Zn})$ needed by our bodies, but all of them can be harmful if ingested in heavily metal-contaminated foods or beverages (Food Standards Agency [FSA], 2010). Recent trends in food safety issues have generated concerns over the presence and levels of heavy metals in cocoa. For instance, the American Environmental Safety Institute took legal action in 2002 against chocolate manufacturers, for excessive levels of $\mathrm{Pb}$ and $\mathrm{Cd}$ found in chocolate (Anderson, 2011). Other reports of heavy metals $(\mathrm{Cd}, \mathrm{Cu}$ and $\mathrm{Ni}$ ) in cocoa beans and chocolates are also of concern to cocoa producers (Dahiya, Karpe, Hedge, \& Sharma, 2004; dos Santos et al., 2005; Jalbani, Kazi, Afridi, \& Arain, 2009). Consequently, international legislative bodies, as well as chocolate manufacturing countries have introduced new regulations for the protection of the health of their consumers (Ducos, Hamester, \& Godula, 2010; Dickson, 2011; European Food Safety Authority [EFSA], 2011. In this respect, reliable methods for determining heavy metals in cocoa and chocolate are required for enforcement of such regulations.

Most analytical methods for metal analyses in cocoa require the chemical decomposition of samples, followed by instrumental detection of the metals. Typically, heavy metals may be extracted from cocoa beans and cocoa products with different oxidizing acids using a variety of techniques. Some of these acids include nitric (Onianwa, Adetola, Iwegbue, Ojo, \& Tella, 1999; Mounicou, Szpunar, Lobinski, Andrey, \& Blake, 2002), hydrochloric (Ano, Odoemelam, \& Ekwueme, 2007), nitric/perchloric (Dahiya et al., 2005; Srogi, 2006) and nitric acid/hydrogen peroxide (Güldaş, Adnan, \& Biricik, 2008), with wet digestion and dry ashing representing 
the two main methods by which metals in these samples are extracted (Soylak, Colak, Tuzen, Turkoglu, \& Elci, 2006).

Wet digestion includes the extraction of samples by an acid or mixtures of acids in open boiling tubes heated on hot plates, with tubes held in aluminum heating blocks (Dahiya et al., 2005; Korn et al., 2008; Duran, Tuzen, \& Soylak, 2009), or in closed or pressurized digestion vessels with thermal (Mounicou et al., 2002) or microwave heating (Srogi, 2006; Güldaş et al., 2008; Dickson, 2010). In contrast, dry ashing is done through thermal decomposition of samples in crucibles in a muffle furnace, followed by dissolution of the metals in the ash by acids (Lee \& Low, 1985; Onianwa et al., 1999; Jorhem \& Engman, 2000; Güldaş, 2008). The metals in sample extracts are subsequently determined using electrochemical (Karadjova, Girousi, Iliadou, \& Stratis, 2000) or spectroscopic techniques, such as atomic absorption spectroscopy (AAS) (Srogi, 2006; Güldaş et al., 2008) and inductively coupled plasma mass spectrometry (ICP-MS) (Mounicou et al., 2002).

A number of these procedures available for the determination of heavy metals in cocoa beans and cocoa products are costly, in terms of capital and recurrent costs, time-consuming and hazardous. However, regardless of method used, it is essential that cost-effective and robust analytical methods be developed to ensure accurate and precise analyses for monitoring and control of heavy metals in cocoa. In many cocoa-producing countries, the ability to monitor the levels of heavy metals in exported cocoa beans is essential in meeting food safety standards used by buyers, but many test methods require equipment, reagents and technical expertise not readily afforded in many countries.

For this study, a simple and inexpensive wet digestion method using nitric acid and open tube extraction of cocoa beans and chocolate, followed by flame atomic absorption spectroscopic determination of selected heavy metals $\mathrm{Cd}, \mathrm{Cu}, \mathrm{Ni}, \mathrm{Pb}$ and $\mathrm{Zn}$ is described. The procedure was systematically optimized with respect to acid:sample ratios, digestion time and overall sample extraction, to produce a cost-effective, sensitive method of analysis, with high sample throughput.

\section{Materials and Methods}

All water used for sample preparation and cleaning of glassware in this study was glass-distilled and then deionized. In order to avoid trace metal contamination, laboratory glassware and other utensils used in all analyses, were washed with a suitable detergent, soaked in an acid bath of $2 \mathrm{M}$ nitric acid for at least 24 hours, rinsed in distilled deionized water and dried in an oven at $50{ }^{\circ} \mathrm{C}$. All reagents used in this study were of analytical grade. Nitric acid (J. T. Baker) was added to sample using calibrated dispensers (Bibby Sterilin Ltd, UK).

\subsection{Instrumentation}

\subsubsection{Heating and Digestion System}

Part of the equipment used for extraction of heavy metals from samples was locally fabricated, namely two aluminum alloy blocks $(30 \times 30 \times 5.5 \mathrm{~cm})$ each drilled in an $8 \times 8$ grid of holes, each $4.5 \mathrm{~cm}$ deep and $2.5 \mathrm{~cm}$ in diameter, with a total capacity of 128 spaces for $15 \times 2.3 \mathrm{~cm}$ borosilicate boiling tubes (Sigma-Aldrich, USA). These blocks were used for sample digestion by heating on a $78 \times 30 \mathrm{~cm}$ hot plate (Thermo Fisher Scientific, Lindberg/Blue M) calibrated and set at $130^{\circ} \mathrm{C}$ for sample digestion.

Holes for mercury thermometers $\left(0-300^{\circ} \mathrm{C}\right)$ were drilled at regular intervals among the tube holes, to allow the block temperature to be monitored throughout sample digestions. The settings on the hot plate and the corresponding temperatures of the heating blocks were first assessed, to determine the setting of $130 \pm 5^{\circ} \mathrm{C}$ in the blocks. Once determined, the positions of the temperature settings were marked, corresponding to the block temperatures required, so that sample digestions could be performed efficiently, with the thermometers being used to confirm the temperatures reached.

\subsection{Heavy Metal Determinations}

A flame atomic absorption spectrophotometer, (Varian SpectrAA Model 880, Australia), was used for the determination of metals throughout this study. A range of working calibration standards (Spectrosol, BDH, UK) of cadmium, copper, nickel and zinc was prepared daily when required and used to optimize the response of the instrument for each element. These analyte standards also allowed sample metal concentrations to be determined using linear or non-linear regression as appropriate.

\subsection{Sample Preparation of Cocoa nibs}

Fermented and dried cocoa beans were oven-dried in aluminum foil at $50{ }^{\circ} \mathrm{C}$ to constant mass (about 12 hours) to remove residual moisture. Dried beans were left to cool and later carefully cracked to separate the nibs from the 
shells, which were then ground separately in acid-washed ceramic mortars and pestles, sieved through $750 \mu \mathrm{m}$ stainless steel sieves, mixed well and stored in clean plastic containers for analysis.

\subsection{Optimization and Validation of Heavy Metal Determinations}

The procedure to determine the heavy metals was optimized using $0.5 \mathrm{~g}$ aliquots of a homogenous ground cocoa nib sample (section 2.3). Optimization consisted of varying both the sample digestion time (intervals of 2, 4, 6, 8 hours) and volume $(5,7.5,10,12.5,15 \mathrm{~mL})$ of concentrated nitric acid for the digestion. This was done to establish an optimal time and acid volume that would yield the highest concentration of each heavy metal recovery from a sample. The method was validated using Certified Reference Materials (CRM), namely National Institute of Standards and Technology (NIST, USA) SRM 2384 baking chocolate for $\mathrm{Cu}$ and $\mathrm{Zn}$, but unfortunately lacked certified levels for $\mathrm{Cd}$ and $\mathrm{Ni}$. In spite of intensive efforts, no cocoa powder or other cocoa product CRM certified for these metals was available from international suppliers. Consequently, NIST SRM 1570a spinach leaves containing certified values for the four metals was used to validate and conduct quality control checks of the method developed. In addition, a sample of locally produced cocoa beans containing the four metals was finely ground and sieved $(<100 \mathrm{~nm})$, to produce an in-house control sample. This control sample was analyzed alongside every batch of CRM and cocoa samples being investigated in a national study, over a period of two years. This allowed the variability of the test method with a cocoa sample to be monitored, as well as its accuracy and precision to be controlled with the CRM.

\subsection{Chemical Analysis}

Each sample was weighed out in triplicate $(0.5 \mathrm{~g})$ into boiling tubes for analysis. To each analysis sample, $10 \mathrm{~mL}$ concentrated analytical grade nitric acid (JT Baker, USA) was added by a reagent dispenser and mixed well in a ventilated fume hood. Sample tubes were covered with clean glass plates to prevent aerial contamination and allowed to pre-digest overnight (12-15 hours) at room temperature. Reagent sample blanks were prepared simultaneously. The pre-digested samples were then refluxed on an alloy-block heater set at $130-135^{\circ} \mathrm{C}$ for 6 hours, to completely digest samples. Samples were swirled at intervals during the process, to ensure that all the material was digested.

After acid digestion, samples were cooled to room temperature, $5 \mathrm{~mL}$ deionized water was added to dilute the contents of each boiling tube and the extract filtered through Whatman no. 542 filters into $25 \mathrm{~mL}$ volumetric flasks. Each solution was made up to volume with deionized water rinses of the residues, mixed thoroughly and analyzed by flame atomic absorption spectrometry.

\subsection{Quality Control}

Sample blanks were prepared with every batch of samples, to correct sample readings for any background or contamination levels of heavy metals in reagents, filters or distilled water used. Calibration check standard solutions were also analyzed at regular intervals ( 1 in every 10 samples) during sample analyses, to monitor and control responses of the atomic absorption spectrometer.

Once the test method was validated with the CRM, its reproducibility was further monitored and controlled in a study which investigated heavy metals in cocoa. For each batch of cocoa samples, SRM 1570a and SRM 2384 were analyzed over a 2-year period. Additionally, a homogenous cocoa nib sample prepared as described in Section 2.3 was analyzed with every batch of samples and CRM, to check the reproducibility of heavy metal analyses over this time. This cocoa nib sample was thus used as an In-house Quality Control Material (IQCM), together with the CRM to monitor the ongoing quality of the method of analysis.

\subsection{Statistical Analysis}

Statistical comparisons among mean concentrations of each selected metal were evaluated, using Analysis of Variance (ANOVA) at p 0.05, with statistical software Minitab (version 16), 2010.

\section{Results and Discussion}

\subsection{Optimization of Experimental Conditions}

Table 1 illustrates mean heavy metal concentrations \pm standard deviations (SD) of triplicate $0.5 \mathrm{~g}$ aliquots of a ground and sieved cocoa nib sample at different digestion times and volumes respectively. One-way ANOVA with Fisher's test at 95\% C.L. showed significant differences $(p<0.05)$ among mean values between 4 and 6 hours digestion time for $\mathrm{Cu}, \mathrm{Ni}$ and $\mathrm{Zn}$, but not for $\mathrm{Cd}$. In comparison, $10 \mathrm{~mL}$ nitric acid with $0.5 \mathrm{~g}$ sample produced significantly higher $(\mathrm{p}<0.05)$ recoveries of $\mathrm{Cu}$ than the other volumes used, while acid volume was not a significant factor for $\mathrm{Cd}, \mathrm{Ni}$ and $\mathrm{Zn}$ recoveries. Consequently, $10 \mathrm{~mL}$ nitric acid with $0.5 \mathrm{~g}$ sample, digested for 6 hours were chosen as optimal for the extraction of the four metals from the cocoa bean sample. Similar 
conditions were subsequently used to validate the test method using the two CRM, to determine the accuracy and precision of the test method. The local cocoa nib sample was also analyzed alongside the CRM, to determine its metal concentrations and to allow its use as an Internal Quality Control Material (IQCM) in monitoring the consistency of recovery of the four metals over an extended period.

Table 1 . Mean heavy metal concentrations $(n=3) \pm$ SD of cocoa nib sample for different digestion times and volumes

\begin{tabular}{lllll}
\hline \multirow{2}{*}{ Digestion Time (hours) } & \multicolumn{4}{l}{ Mean metal concentration $(\mu \mathrm{g} / \mathrm{g})$} \\
\cline { 2 - 5 } & $\mathrm{Cd}$ & $\mathrm{Cu}$ & $\mathrm{Ni}$ & $\mathrm{Zn}$ \\
\hline 2 & $1.85 \pm 0.13$ & $14.69 \pm 0.32$ & $2.71 \pm 0.31$ & $21.06 \pm 0.48$ \\
4 & $1.86 \pm 0.11$ & $13.63 \pm 0.45$ & $2.49 \pm 0.00$ & $20.46 \pm 0.19$ \\
6 & $1.93 \pm 0.10$ & $14.15 \pm 0.19$ & $2.90 \pm 0.04$ & $20.02 \pm 0.37$ \\
8 & $2.00 \pm 0.06$ & $13.47 \pm 0.23$ & $3.03 \pm 0.04$ & $19.93 \pm 0.44$ \\
Acid Volume (mL) & & & & \\
5 & $1.60 \pm 0.09$ & $13.25 \pm 0.36$ & $3.25 \pm 0.09$ & $22.17 \pm 0.03$ \\
7.5 & $1.62 \pm 0.09$ & $13.60 \pm 0.22$ & $3.15 \pm 0.05$ & $21.46 \pm 0.51$ \\
10 & $1.92 \pm 0.26$ & $14.02 \pm 0.00$ & $3.31 \pm 0.00$ & $21.81 \pm 0.09$ \\
12.5 & $1.86 \pm 0.14$ & $13.70 \pm 0.18$ & $3.28 \pm 0.04$ & $21.44 \pm 0.29$ \\
15 & $1.81 \pm 0.07$ & $13.92 \pm 0.04$ & $3.28 \pm 0.13$ & $20.49 \pm 0.11$ \\
\hline
\end{tabular}

\subsection{Method Validation}

The optimized method of analysis for the four selected heavy metals was subsequently validated using CRM SRM 1570a and SRM 2384. Percentage recovery results are shown in Table 2.

Table 2. Mean heavy metal concentrations $(\mathrm{n}=15)$ and recoveries from NIST Certified Reference Materials SRM 1570a and SRM 2384

\begin{tabular}{|c|c|c|c|c|c|}
\hline $\begin{array}{l}\text { Certified Reference } \\
\text { Material }\end{array}$ & Metal & $\begin{array}{l}\text { Certified value } \\
\pm \mathrm{SD}(\mu \mathrm{g} / \mathrm{g})\end{array}$ & $\begin{array}{l}\text { Analysis Mean } \\
(\mu \mathrm{g} / \mathrm{g})+\mathrm{SD}\end{array}$ & $\%$ Recovery & RSD \\
\hline \multirow{4}{*}{$\begin{array}{l}\text { SRM 1570a } \\
\text { (Spinach Leaves) }\end{array}$} & $\mathrm{Cd}$ & $2.89 \pm 0.07$ & $2.69 \pm 0.05$ & 95.5 & 4.71 \\
\hline & $\mathrm{Cu}$ & $12.20 \pm 0.6$ & $11.29 \pm 0.69$ & 101.1 & 4.95 \\
\hline & $\mathrm{Ni}$ & $2.14 \pm 0.1$ & $1.94 \pm 0.12$ & 90.7 & 6.19 \\
\hline & $\mathrm{Zn}$ & $82 \pm 3$ & $78.87 \pm 2.71$ & 96.2 & 3.44 \\
\hline \multirow{4}{*}{$\begin{array}{l}\text { SRM } 2384 \text { (Baking } \\
\text { Chocolate) }\end{array}$} & $\mathrm{Cd}$ & NR & 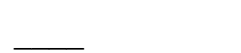 & 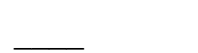 & 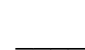 \\
\hline & $\mathrm{Cu}$ & $23.20 \pm 1.2$ & $24.59 \pm 0.41$ & 105.9 & 1.66 \\
\hline & $\mathrm{Ni}$ & NR & 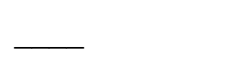 & 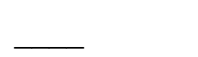 & 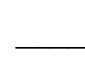 \\
\hline & $\mathrm{Zn}$ & $36.60 \pm 1.7$ & $38.99 \pm 0.84$ & 106.5 & 2.15 \\
\hline
\end{tabular}

RSD: Relative Standard Deviation; NR: Not Reported.

Each detectable metal analyzed in SRM 1570a and SRM 2384 respectively compared well with its certified values, having recoveries ranging from 90.7 to $104.4 \%$. Relative Standard Deviations were also less than $10 \%$, indicating acceptable precisions of analyses for the four metals detected and determined. While the \% recoveries for Ni were only 91\%, such recoveries were similar to those reported by Hseu, 2004; Flores-Meza, 2008; Moradi, 2008 for digestion of other plant materials using nitric acid and may reflect the need for more aggressive extraction techniques, such as use with perchloric or hydrochloric acids to more completely extract $\mathrm{Ni}$ from 
samples. However, such changes would result in greater costs of chemical and analysis times for the analyses. Fortunately, the highly consistent recoveries over two years, of Ni from the NIST 1570a spinach leaves CRM (Table 3), as well as from the IQCM (Table 4), can allow a correction factor to be applied to cocoa sample data for Ni. Nevertheless, based on the results of the two CRM, the optimized method was considered to be accurate and sufficiently precise for the determination of $\mathrm{Cd}, \mathrm{Cu}, \mathrm{Ni}$ and $\mathrm{Zn}$ of cocoa bean and chocolate samples.

\subsection{Quality Control of Method of Analysis}

The test method developed was applied to cocoa beans over two years, with each batch of beans being analyzed together with the CRM 1570a and the Internal Quality Control Material (IQCM) cocoa bean sample. Data generated from 43 CRM samples, each analyzed in triplicate over this period are shown in Tables 3 . The mean CRM recoveries for each detectable metal over this period were consistent with their certified values (Table 2). In addition, the RSD values $(<10 \%)$ for each metal determined demonstrate the high precision and reproducibility of the test method.

Table 3. Mean heavy metal concentrations $(n=43) \pm$ RSD in Certified Reference Material

\begin{tabular}{lllll}
\hline $\begin{array}{l}\text { Certified } \\
\text { Reference } \\
\text { Material }\end{array}$ & \multicolumn{4}{l}{ Mean metal concentration $(\mu \mathrm{g} / \mathrm{g}) \pm \mathrm{RSD}$} \\
\cline { 2 - 5 } & $\mathrm{Cd}$ & $\mathrm{Cu}$ & $\mathrm{Ni}$ & $\mathrm{Zn}$ \\
\hline SRM 1570a & $2.76 \pm 4.71$ & $12.30 \pm 4.95$ & $2.17 \pm 7.83$ & $78.69 \pm 4.26$ \\
\hline
\end{tabular}

RSD: Relative Standard Deviation.

Table 4 similarly provides the results of 43 samples of cocoa nib IQCM over the two-year period. The data show that the analyses for each metal were quite precise and reproducible, since the RSD for mean concentrations from the IQCM were all less than $10 \%$.

Table 4. Mean heavy metal concentrations $(n=43) \pm$ RSD from the cocoa nibs (IQCM)

\begin{tabular}{lllll}
\hline \multirow{2}{*}{ Sample } & \multicolumn{4}{l}{ Mean metal concentration $(\mu \mathrm{g} / \mathrm{g}) \pm \mathrm{RSD}$} \\
\cline { 2 - 5 } & $\mathrm{Cd}$ & $\mathrm{Cu}$ & $\mathrm{Ni}$ & $\mathrm{Zn}$ \\
\hline IQCM & $1.59 \pm 9.59$ & $22.15 \pm 3.45$ & $6.90 \pm 6.31$ & $44.28 \pm 3.74$ \\
\hline
\end{tabular}

RSD: Relative Standard Deviation.

Our optimized, validated and quality controlled procedure is an inexpensive, accurate and reproducible alternative for the quantification of heavy metals in cocoa beans and chocolate. It utilizes only nitric acid (10 mL per sample) for metal extraction, thereby reducing costs compared to other methods that use a combination of acids (Dahiya et al., 2005; Srogi, 2006; Güldaş, 2008). Additionally, while other methods require expensive apparatus for digestion of samples such as closed high-pressure PTFE-lined digestion vessels (Mounicou et al., 2002; Association of Official Analytical Chemists [AOAC], 2005; Güldaş, 2008; Jalbani et al., 2009), this method uses standard borosilicate boiling tubes with open tube wet digestion. In comparison, dry ashing (Quevauviller, 1995; Stephen \& Piotr, 2005) usually requires $>12$ hours for the preparation of a batch of samples and cross-contamination is difficult to control.

While the dissolution and total decomposition of samples are required for the release of trace elements, the use of oxidizing acids can produce violent reactions upon digestion shortly after reagent additions (Twyman, 2005), resulting in sample loss. Our method includes a 12-15 hour pre-digestion procedure which partially decomposes samples at room temperature, safely venting nitrogen oxides and minimizing excessive foaming and sample loss during subsequent heated sample digestion. Dispensing of the acid into the sample tubes takes a few seconds each, the pre-digestion requires no operator attention and the method using our heating block system can digest up to 128 samples per batch every 6 hours, with little operator attention. The capacity of this system far exceeds any of the commercially available block digestion systems and uses regular laboratory hotplates instead of dedicated equipment. The cost of our system was estimated to be 2 to 3 times less those of commercially manufactured equipment (Perkin Elmer, DigiPrep MS, AIM600). Since the aluminum blocks can be inexpensively fabricated to specification by mechanical workshops. 


\section{Conclusions}

A reliable test method has been developed for the analysis of selected heavy metals $\mathrm{Cd}, \mathrm{Cu}, \mathrm{Ni}$ and $\mathrm{Zn}$ in cocoa beans and chocolate. The analytical procedure was optimized and validated and provides a simple, rapid and cost-effective method for generating accurate and precise results. Two CRM were used to validate the test method, while a locally generated cocoa bean sample was used as an In-house Control Material to monitor the consistency of cocoa bean analyses over two years. The recoveries of $\mathrm{Cd}, \mathrm{Cu}$ and $\mathrm{Zn}$ was $>95 \%$, while nickel was $91 \%$. However, the highly consistent recoveries of nickel over two years, from both the CRM and the local cocoa bean sample, can allow a correction factor to be applied for this metal in cocoa and chocolate samples. Compered to commercial sample extraction systems available, our system requires significantly cheaper equipment and low operator attention, compared to those of previously reported methods.

\section{References}

Ano, A. O., Odoemelam, S. A., \& Ekwueme, P. O. (2007). Lead and Cadmium Levels in Soil and Cassava(Manihot esculenta grantz) along Enugu-PortHarcourt Express Way in Nigeria. Elect. J. Environ. Agric. Food Chem, 6(5), 2024-2031.

Association of Official Analytical Chemist (AOAC). (2005). Official Method 972.40A. In W. Horwitz (Ed.), Official Methods of Analysis of AOAC International (18th ed.), Gaithersburg, MD, USA: Association of Official Analytical Chemists.

Anderson, H. (2002). Law Suit Filed over Toxic Metals in Chocolate. United Press International, Inc. Top News. Retrieved, March 16, 2011, from http://www.upi.com/Top_News/2002/05/08/Suit-filed-over-toxic-metals-in-chocolate/UPI-4778102089553 $5 /$

Dahiya, S., Karpe, R., Hegde, A. G., \& Sharma, R. M. (2005). Lead, Cadmium and Nickel in Chocolates and Candies from Suburban Areas of Mumbai, India. J. Food Compos. Anal., 18, 517-522. http://dx.doi.org/10.1016/j.jfca.2004.05.002

Dos Santos, W. N., da Silva, E. G., Fernandes, M. S., Araujo, R. G., Costa, A. C., Vale, M. G., \& Ferreira, S. L. C. (2005). Determination of copper in powdered chocolate samples by slurry sampling flame atomic-absorption spectrometry. Analytical and Bioanalytical Chemistry, 382, 1099-1102. http://dx.doi.org/10.1007/s00216-005-3252-y

Ducos, S., Hamester, M., \& Godula, M. (2010). ICP-MS for Detecting Heavy Metals in Foodstuffs: The Technology can Analyze 50 Samples in an Hour.

Dickson, H. (2010). The Analysis of Cadmium in Chocolate by Graphite Furnace Atomic Absorption Spectrometry. Thermo Fisher Scientific Retrieved, 18 April, 2010, from http://www.analiticaweb.com.br/newsletter/10/43034_CadmiumChocolate_AA.pdf

Duran, A., Tuzen, M., \& Soylak, M. (2009). Trace Metal Contents in Chewing Gums and Candies Marketed in Turkey. Environ. Monit. Assess, 149(1), 283-289. http://dx.doi.org/10.1007/s10661-008-0202-0

European Food Safety Authority (EFSA). (2011). Metal Contaminants in Food. Retrieved, 16 April, 2011 from http://www.efsa.europa.eu/en/topics/topic/metals.htm

Flores-Meza, D. M. (2008). Modeling metal uptake by barley plants (Hordeum vulgare) in nutrient solution. (Doctoral dissertation). Available from ProQuest Dissertation \& Theses: Full Text (ID:304630280).

Food Standards Agency (FSA). (2010). Metals in the Diet. Retrieved 23 October, 2010, from http://www.food.gov.uk/news/newsarchive/2004/mar/metals

Guldas, M., Adnan, F. D., \& Biricik, F. B. (2008). Determination and comparison of some trace elements in different chocolates types produced in Turkey. Journal of Food Agriculture \& Environment, 6(3\&4), 90-94.

Hseu, Z.-Y. (2004). Evaluating heavy metal contents in nine composts using four digestion methods. Bioresource Technology, 95, 53-59. http://dx.doi.org/10.1016/j.biortech.2004.02.008

Jalbani, N., Kazi, T. G., Afridi, H. I., \& Arain, M. B. (2009). Determination of Toxic Metals in Different Brands of Chocolates and Candies, Marketed in Pakistan. Pak.J.Anal.Environ.Chem., 10, (1-2), 48-52.

Jorhem, L., \& Engman, J. (2000). Determination of Lead, Cadmium, Zinc, Copper, and Iron in Foods by Atomic Absorption Spectrometry after Microwave Digestion: NMKL1 Collaborative Study. J AOAC Int., 83, 1189-1203. 
Karadjova, I., Girousi, S., Iliadou, E., \& Stratis, I. (2000). Determination of $\mathrm{Cd}, \mathrm{Co}, \mathrm{Cr}, \mathrm{Cu}, \mathrm{Fe}, \mathrm{Ni}$ and $\mathrm{Pb}$ in Milk, Cheese and Chocolate. Microchimica Acta., 134(3), 185-191. http://dx.doi.org/10.1007/s006040050065

Korn, M. G. A., da Boa Morte, E. S., Batista dos Santos, D. C. M., Castro, J. T., Barbosa, J. T. P., Teixeira, A. P., ... Korn, M. (2008). Sample Preparation for the Determination of Metals in Food Samples using Spectro-Analytical Methods: A Review. Appl. Spectros. Rev., 43(2), 67-92. http://dx.doi.org/10.1080/05704920701723980

Lee, C. K., \& Low, K. S. (1985). Determination of Cadmium, Lead, Copper and Arsenic in Cocoa, Semi-Finished and Finished Chocolate Products. Pertanika., 8(2), 243-248.

Moradi, A. (2008). Imaging techniques to study nickel-root interactions of the Ni hyperaccumulator plant Berkheya coddii. ETH. http://dx.doi.org/10.3929/ethz-a-005705176

Mounicou, S., Szpunar, J., Lobinski, R., Andrey, D., \& Blake, C. J. (2002). Bioavailability of Cadmium and Lead in Cocoa: Comparison of Extraction Procedures Prior to Size-Exclusion Fast-Flow Liquid Chromatography with Inductively Coupled Plasma Mass Spectrometric Detection (SEC-ICP-MS). J. Anal. Atom. Spec., 17, 880-886. http://dx.doi.org/10.1039/B201639G

Onianwa, P. C., Adetola, I. G., Iwegbue, C. M. A., Ojo, M. F., \& Tella, O. O. (1999). Trace Heavy Metals Composition of some Nigerian Beverages and Food Drinks. Food Chem., 66(3), 275-279. http://dx.doi.org/10.1016/S0308-8146(98)00257-X

Quevauviller, P. (1995). Trends in Trace Element Determinations in Environmental and Food Matrices:

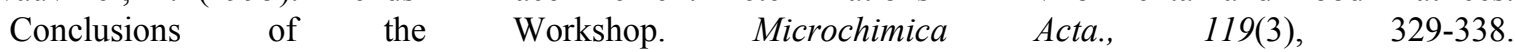
http://dx.doi.org/10.1007/BF01244013

Srogi, K. (2006). Assessment of Selected Heavy Metal Contents in Medicinal Plants, Tea Leaves and Chocolate using Atomic Absorption Spectrometry. Acta Toxicol., 14, 117-128.

Soylak, M., Colak, H., Tuzen, M., Turkoglu, O., \& Elci, L. (2006). Comparison of Digestion Procedures on Commercial Powdered Soup Samples for the Determination of Trace metal Contents by Atomic Absorption Spectrometry. J. Food Drug Anal., 14, 62-67.

Stephen, C., \& Piotr, S. (2005). Determination and Speciation of Trace Elements in Foods. In S. Otles (Ed.) Methods of Analysis of Food Components and Additives (pp. 111-158). CRC Press: Boca Raton, FL, 6, http://dx.doi.org/10.1201/9780203503751.ch6

Twyman, R. M. (2005). Sample dissolution for elemental analysis/wet digestion (pp. 146-153). University of York, York, UK: Elsevier Ltd.

Żukowska, J., \& Biziuk, M. (2008). Methodological evaluation of method for dietary heavy metal intake. Journal of Food Science, 73, 21-29. http://dx.doi.org/10.1111/j.1750-3841.2007.00648.x

\section{Copyrights}

Copyright for this article is retained by the author(s), with first publication rights granted to the journal.

This is an open-access article distributed under the terms and conditions of the Creative Commons Attribution license (http://creativecommons.org/licenses/by/3.0/). 